\title{
The risk factors for postoperative cerebral complications in patients with Stanford type a aortic dissection
}

\author{
Yong Lin ${ }^{*} \mathbb{D}$, Mei-Fang Chen, Hui Zhang, Ruo-Meng Li and Liang-Wan Chen
}

\begin{abstract}
Background: Postoperative cerebral complications (PCC) are common and serious postoperative complications for patients with Stanford type A aortic dissection (AAD). The aim of this study was to evaluate the risk factors for PCC in these patients and to provide a scientific basis for effective prevention of PCC.

Methods: In this retrospective case-control study, 125 patients with AAD who underwent thoracotomy in our department from October 2017 to October 2018 in the department of cardiovascular surgery, Fujian Medical University Union Hospital were divided into two groups: patients with PCC $(n=12)$, and patients without PCC $(n=113)$. The general clinical data, the types of corrective surgeries, the intraoperative situations, the postoperative complications, and the midterm outcomes of the patients were analyzed.

Results: The patients with PCC were significantly older than the patients without PCC $(P=0.016)$, and the incidence of the preoperative cerebral disease history in the patients with PCC was significantly higher than those of the PCC (-) group $(P=0.024)$. The Euro SCORE II of patients with PCC was dramatically higher than the patients without PCC $(P=0.005)$. There were significant differences between the two groups in terms of the duration of cardiopulmonary bypass $(C P B)(P=0.010)$ and the length of moderate hypothermic circulatory arrest $(\mathrm{MHCA})$ combined with selective cerebral perfusion (SCP) $(P=0.000)$. The monitoring of $\mathrm{rCSO}_{2}$ indicated that there was significant difference between the two groups in terms of the bilateral baseline $(P=0.000)$. Patients with PCC were observed to have experienced significantly longer intubation times $(P=0.000)$, ICU stays $(P=0.001)$, and postoperative hospital stays $(P=0.009)$, and they also had dramatically higher rates of pulmonary infection $(P=0.000)$, multiple organ dysfunction syndrome $(P=0.041)$ and tracheotomy $(P=0.022)$ after surgeries. The duration of MHCA+SCP (OR:9.009, $P=0.034)$ and the average baseline value of $\mathrm{rCSO}_{2}(\mathrm{OR}: 0.080, P=0.009)$ were ultimately identified as significant risk factors.
\end{abstract}

Conclusions: PCC has a serious influence on the prognoses of patients following surgical treatment with $A A D$. The duration of MHCA+SCP and the average baseline value of $\mathrm{rCSO}_{2}$ were the independent risk factors for PCC.

Keywords: Postoperative complications, Circulatory arrest, deep hypothermia induced, Oximetry, Aneurysm, dissecting

\footnotetext{
* Correspondence: birdman1983@163.com

Department of Cardiovascular Surgery, Fujian Medical University Union

Hospital, No. 29 Xinquan Road, Fuzhou City 350001, Fujian Province, People's

Republic of China
}

(c) The Author(s). 2019 Open Access This article is distributed under the terms of the Creative Commons Attribution 4.0 International License (http://creativecommons.org/licenses/by/4.0/), which permits unrestricted use, distribution, and reproduction in any medium, provided you give appropriate credit to the original author(s) and the source, provide a link to the Creative Commons license, and indicate if changes were made. The Creative Commons Public Domain Dedication waiver (http://creativecommons.org/publicdomain/zero/1.0/) applies to the data made available in this article, unless otherwise stated. 


\section{Background}

Postoperative cerebral dysfunction is the most common complication after the surgery for Stanford type A aortic dissection (AAD), and it has a negative effect that cannot be ignored in the postoperative rehabilitation of patients with AAD. Although the intraoperative cerebral protection strategy has been modified in recent decades, the morbidity due to postoperative cerebral complications (PCC) have been reported to be $6.4 \% \sim 16.9 \%$ in cardiovascular surgical centers around the world [1-3]. Therefore, it is extremely important for cardiovascular surgeons and ICU physicians to explore the pathogenesis of PCC. The aim of this study was to evaluate the risk factors of postoperative cerebral dysfunction in these patients and to provide a scientific basis for the effective prevention of PCC.

\section{Methods}

Two hundred consecutive patients with AAD who underwent thoracotomy in our department from October 2017 to October 2018 were enrolled in this retrospective casecontrol study. Then, the patients were divided into two groups: patients with PCC and patients without (Fig. 1). The general clinical data, types of corrective surgeries, intraoperative situations, postoperative complications, and midterm outcomes (12 months) of the patients were analyzed by telephone follow-up or out-patient review.

\section{Exclusion criteria}

1. Patients who were younger than 18 years old.

2. Patients who were died before surgeries.

3. Patients with an abnormal preoperative consciousness.

4. Patients and/or their relatives who did not agree to participate in this clinical study.

5. Patients who were lost within the 12-month follow-up period.

\section{Diagnostic criteria of the postoperative cerebral complications}

The PCC included new-onset stroke, syncope, delirium, postoperative cognitive dysfunction (POCD), delayed emergence from anesthesia (DEA) and coma. The diagnosis of a stroke was based on the National Institutes of Health Stroke Scale (NIHSS) [4]. Syncope was defined as a transient loss of consciousness and was characterized by a rapid onset, short duration, and spontaneous complete recovery [5]. The confusion assessment method for the intensive care unit (CAM-ICU) [6] was applied for the evaluation of postoperative delirium (POD) and POCD. The Glasgow Coma Scale (GCS) [7] was used to objectively define coma in the two groups of patients after their surgeries. The patients whose response to stimulation occurred more than 60 90 min after the surgeries were recognized as having a

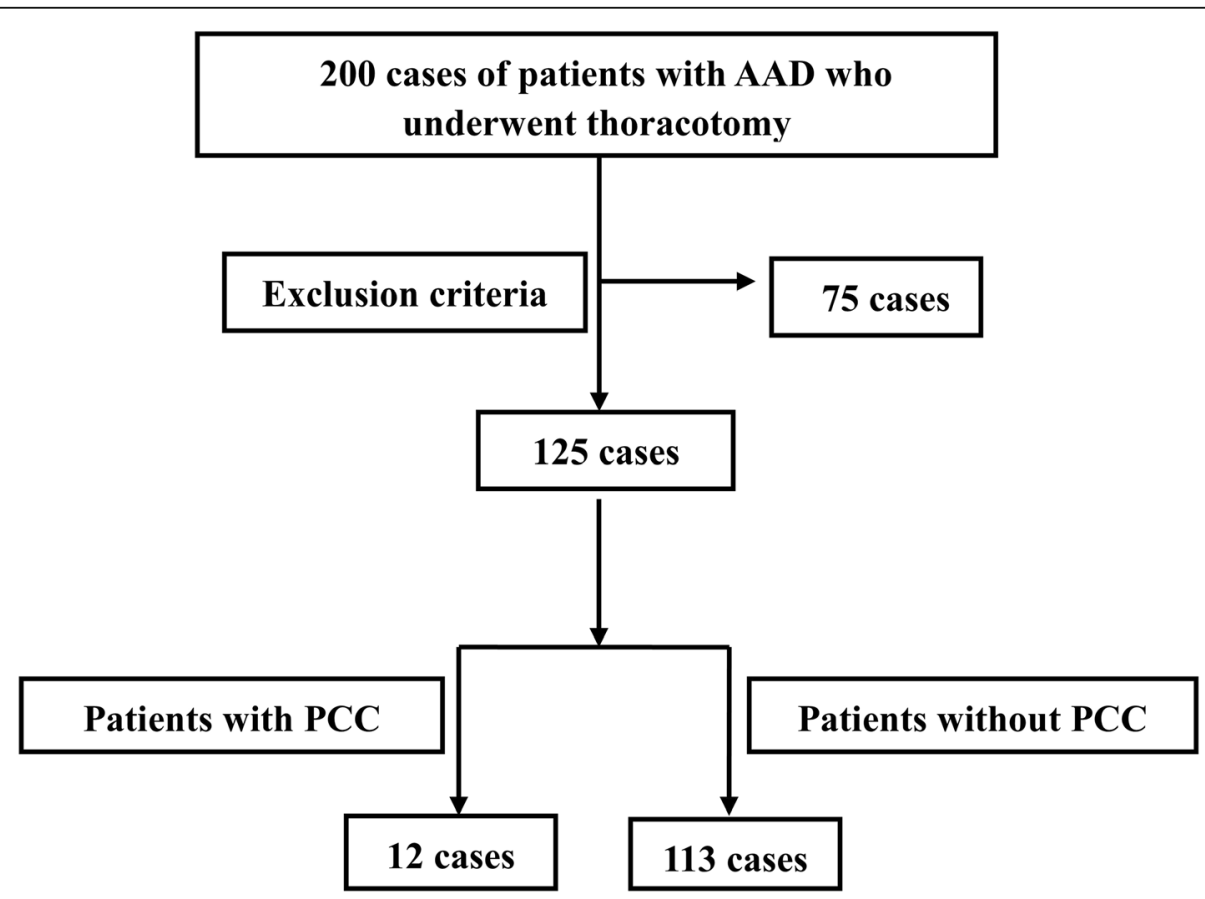

Fig. 1 Flow Chart. One hundred and twenty-five patients with Stanford type A aortic dissection who underwent thoracotomy were selected from 200 patients based on the exclusion criteria, and they were divided into two groups: patients with PCC $(n=12)$, and patients without PCC $(n=113)$. Seventy-five patients were excluded from this study according to the exclusion criteria. AAD: Stanford type A aortic dissection; PCC: postoperative cerebral complications 
delayed emergence from anesthesia [8], and this diagnosis should exclude the possibility of the other types of cerebral dysfunction mentioned above.

All of the diagnoses of PCC were confirmed by two experienced neurologists. Deeply sedated patients, confirmed by the monitoring sedation status system on the Richmond Agitation Sedation Scale (RASS) [9], did not receive an evaluation of cerebral function until they recovered from anesthesia.

\section{Protocols of anesthesia}

Combined intravenous-inhalation anesthesia was applied in the patients. The nasopharyngeal temperature and the rectal temperature were also monitored. Transesophageal echocardiography (TEE) was applied to monitor the intraoperative hemodynamics. Autologous blood transfusion was used to reduce the need for allogeneic blood transfusion. The balances of cerebral oxygen metabolism of the patients were measured by regional cerebral oxygen saturation $\left(\mathrm{rcSO}_{2}\right)$ with the Regional Oximetry System INVOS $^{\text {mi }} 5100 \mathrm{C}$, Medtronic, USA). The bispectral index (BIS), which was measured by the BIS Monitoring System (VISTA, USA), was used to measure the depth of anesthesia.

Mechanical ventilation was performed after endotracheal intubation and was applied to provide end tidal $\mathrm{CO}_{2}$ volumes $\left(\mathrm{PetCO}_{2}\right)$ of $35 \sim 40 \mathrm{mmHg}$, a FiO ${ }_{2}$ of $50 \sim 100 \%$, a tidal volume of $6 \sim 8 \mathrm{ml} / \mathrm{kg}$, a respiratory rate of $10 \sim 12$ breaths/ min and an adequate positive end-expiratory pressure (PEEP). The maintenance of anesthesia was implemented by an intravenous injection of $4 \sim 8 \mathrm{mg} / \mathrm{kg} / \mathrm{h}$ propofol and $1 \sim 2 \mu \mathrm{g} / \mathrm{kg} / \mathrm{h}$ sufentanil along with intermittent intravenous injections of cisatracurium.

During the surgery, the values of $\mathrm{scSO}_{2}$ were maintained at or above $70 \%$ of the baseline threshold. Cerebral desaturation was defined as a decrease in the saturation value below the absolute value of $50 \%$ or $70 \%$ of the baseline for $15 \mathrm{~s}$. The mean and minimum values of the $\mathrm{rCSO}_{2}$, as well as the area under the curve (AUC) of the $\mathrm{rcSO}_{2}$ values below the line of the previously mentioned cerebral desaturation values, were collected for further analysis.

\section{Surgical procedures}

During surgery, A sternal incision was performed. To establish cardiopulmonary bypass (CPB), the arterial cannula was placed in the right femoral artery and/or the right axillary artery, and the drainage tube was placed in the right atrium. The $\mathrm{CPB}$ flow rate was $2.4 \sim 2.6 \mathrm{~L} / \mathrm{kg} / \mathrm{min}$. The intermittent cold blood cardioplegia was perfused through the left and right coronary arteries for myocardial protection. The following procedures, including the triple-branched stent graft implantation [10] and the Sun's procedures were described in the previous literature [11].

\section{Protocol to address intraoperative cerebral desaturation} The positions of the patients were checked first to exclude the compression of the cervical great vessels when the intraoperative cerebral desaturation occurred. Then, the parameters of the mechanical ventilator (before or after $\mathrm{CPB}$ ) or the oxygenator (during $\mathrm{CPB}$ ) were adjusted to maintain the arterial pressure of $\mathrm{CO}_{2}$ $\left(\mathrm{PaCO}_{2}\right)$ above $40 \mathrm{mmHg}$. Metaraminol or noradrenaline was used to elevate the mean arterial pressure (MAP) to above $60 \mathrm{mmHg}$. A cardiotonic was administered if there was a poor cardiac index (below $2.0 \mathrm{~L} / \mathrm{m}^{2} / \mathrm{min}$ ), and adequate blood volume was confirmed by TEE. The BIS value was maintained at or below 50 during the $\mathrm{CPB}$ to ensure that patients were in a state of deep anesthesia. Other methods to prevent cerebral hypoxia included increasing the pump flow, increasing the $\mathrm{FiO}_{2}$ and performing allogeneic blood transfusion.

\section{Follow-up}

Telephone contact or out-patient review with the patients was maintained after discharge. Every month in the first year, the patients received echocardiographies, chest radiographies, and bilateral carotid artery Doppler examinations. At 1 month and 3 months after surgery, the patients received aortic computed tomography angiography (CTA) examinations, which were then performed annually.

\section{Statistical analysis}

SPSS software (version 19.0, IBM, USA) was used for the statistical analyses. Descriptive statistical analyses, as well as Wilcoxon rank sum tests, were used to analyze the measurement data. The chi-square test or Fisher's exact test were used to analyze the numerical data. Multivariate logistic regression analysis was used to analyze the count data. Statistical significance was defined as $P<0.05$.

\section{Results \\ General clinical data}

Seventy-five patients were excluded from this study after meeting the exclusion criteria described above, including 9 cases who were younger than 18 years old, 42 cases with an abnormal preoperative consciousness, 8 cases died before surgeries, 13 cases who did not agree to participate in this clinical study, 3 cases who were lost within the 12-month follow-up period. One hundred twenty-five cases were included after applying the exclusion criteria. Then, the patients were divided into two groups: patients with PCC $(n=12)$ and patients without $(n=113)$.

The primary analyses revealed that the patients in the PCC (+) group were significantly older than the patients in the PCC $(-)$ group $(58.4 \pm 8.4$ years vs $49.4 \pm 13.4$ years, $P=0.016)$, and the incidence of preoperative cerebral 
disease history in the patients of the PCC $(+)$ group was significantly higher than that of the PCC (-) group (16.7\% vs $0.9 \%, P=0.024)$. The Euro SCORE II of patients in the PCC $(+)$ was dramatically higher than the patients of the PCC (-) group (11.9 \pm 2.7 vs $9.0 \pm 3.4, P=0.005)$. There were no significant differences between the patients in the two groups in terms of gender, body mass index (BMI), personal history, underlying diseases (except for preoperative cerebral disease history), New York Heart Association (NYHA) class, etiologies, ultrasound cardiogram (UCG) results, preoperative complications due to aortic dissection, scale of aortic dissection and American Society of Anesthesiologists (ASA) class (Table 1).

\section{Surgical and perioperative treatments}

The chi-square test revealed that there were no significant differences in the types of surgical procedures between the patients in the two groups. The Wilcoxon rank sum tests also indicated that there were significant differences between the two groups in terms of the duration of $\mathrm{CPB}(165.4 \pm 42.5 \mathrm{~min}$ vs $134.8 \pm 21.5 \mathrm{~min}$, $P=0.010)$ and the length of moderate hypothermic circulatory arrest combined with selective cerebral perfusion $(\mathrm{MHCA}+\mathrm{SCP})(20.3 \pm 2.1 \mathrm{~min}$ vs $15.5 \pm 2.7 \mathrm{~min}$, $P=0.000)$. The monitoring of $\mathrm{rcSO}_{2}$ indicated that there were no significant differences between the two groups in terms of intraoperative $\mathrm{rcSO}_{2}$ except for the average value of bilateral $\mathrm{rCSO}_{2}$ at baseline $(48.2 \pm 3.3 \%$ vs $66.7 \pm$ $11.7 \%, P=0.000)$. However, the duration of surgery, aortic cross-clamping, the mean value of the intraoperative BIS index, the volumes of blood loss and perioperative allogeneic transfusion were not significantly different in the patients in these two groups (Table 2).

\section{Postoperational situation}

Twelve $(12 / 125,9.6 \%)$ patients with postoperative cerebral complications were observed. The Wilcoxon rank sum tests showed that the anesthesia recovery periods of the patients in the $\mathrm{PCC}(+)$ group were shorter than those of the patients in the PCC (-) group, but there was no significant difference. Two cases of newly onset stroke confirmed by computed tomography (CT) or magnetic resonance imaging (MRI) $(2 / 125,1.6 \%), 1$ case of syncope $(1 / 125,0.8 \%), 2$ cases of POD $(2 / 125,1.6 \%), 3$ cases of POCD (3/125, 2.4\%), 2 cases of DEA (2/125, $1.6 \%), 2$ cases of coma $(2 / 125,1.6 \%)$ and 2 cases of postoperative paraplegia were observed in this study. Patients from the PCC $(+)$ group were observed to have experienced significantly longer intubation times $(69.3 \pm 28.8 \mathrm{~h}$ vs $33.3 \pm 24.2 \mathrm{~h}, P=0.000)$, ICU stays $(127.3 \pm 72.0 \mathrm{~h}$ vs $63.5 \pm 51.3 \mathrm{~h}, P=0.001$ ), and postoperative hospital stays $(32.0 \pm 16.7 \mathrm{~d}$ vs $21.2 \pm 13.0 \mathrm{~d}, P=0.009)$, and they also had dramatically higher rates of pulmonary infection (50.0\% vs $7.1 \%, P=0.000$ ), multiple organ dysfunction syndrome (MODS) $(25.0 \%$ vs $5.3 \%, P=0.041)$, gastrointestinal complications $(25 \%$ vs $5.3 \%, P=0.041)$ and tracheotomy (33.3\% vs $8.0 \%, P=0.022)$ after surgery. However, no significant differences were observed in the non-neurological complications, including reoperations for bleeding, heart dysfunction, myocardial infarction, lethal arrhythmia, renal insufficiency, wound infection, or sepsis between the patients in these two groups. The rates of the use of extracorporeal membrane oxygenation (ECMO) were confirmed to be approximately equal between the two groups (Table 3).

Five cases of death $(5 / 125,4.0 \%)$ were observed in this study, including 4 cases that occurred in the hospital and 1 case that occurred after discharge. Three of these deaths were attributed to multiple organ dysfunction syndrome (MODS) and 2 were attributed to low cardiac output syndrome (LCOS). Fisher's exact test showed that there was no significant difference in the mortalities of the patients in the two groups, but we observed an ascending trend in mortality after the surgeries in the patients of the PCC $(+)$ group compared with the patients in the PCC (-) group $(16.7 \%$ vs $2.7 \%, P=0.072)$. Wilcoxon rank sum tests also showed that patients in the PCC (+) group spent remarkably more money than the patients in the PCC (-) group $(272,911.0 \pm 60,495.8$ RMB vs $224,651.5 \pm 61,219.9$ RMB, $P=0.015$ ) (Table 3 ).

\section{The results of multivariate logistic regression analysis}

A total of 6 variables including age, history of the cerebral diseases, Euro SCORE II, duration of CPB, duration of $\mathrm{MHCA}+\mathrm{SCP}$ and average $\mathrm{rCSO}_{2}$ bilateral baseline were analyzed in the stepwise logistic regression model to identify the independent risk factors for PCC. The multivariate logistic regression analysis showed that the duration of MHCA+SCP and the average baseline value of $\mathrm{rcSO}_{2}$ from the bilateral brain before anesthesia induction were the independent risk factors for PCC (OR: 9.009, $P=0.034$ and OR: $0.080, P=0.009$ ) (Table 4).

\section{Follow-up}

Three patients were lost within the 12-month follow-up period and were excluded from this study. One incidence of death after discharge was observed in the PCC $(+)$ group and that was attributed to recurrence of the aortic dissection.

\section{Discussion}

Although the technology of cerebral protection has been improved in the last few decades, the morbidity of PCC after surgery for AAD occurs at such a high frequency that we cannot ignore the harmful impact of it. In this study, patients with PCC had dramatically higher rates of pulmonary infection and tracheotomy after surgery, and this was relevant with the longer duration of 
Table 1 Clinical data

\begin{tabular}{|c|c|c|c|}
\hline Category of clinical data & $\begin{array}{l}\text { PCC (+) } \\
n=12\end{array}$ & $\begin{array}{l}\text { PCC (-) } \\
n=113\end{array}$ & $P$ \\
\hline Age & $58.4 \pm 8.4$ & $49.4 \pm 13.4$ & 0.016 \\
\hline Gender & & & 1.000 \\
\hline Male & $11(91.7 \%)$ & $96(85.0 \%)$ & \\
\hline Female & $1(8.3 \%)$ & $17(15.0 \%)$ & \\
\hline BMl & $24.1 \pm 2.8$ & $24.4 \pm 3.3$ & 0.987 \\
\hline Active smoking & $6(50.0 \%)$ & $48(42.5 \%)$ & 0.761 \\
\hline Alcoholism & $1(8.3 \%)$ & $11(9.7 \%)$ & 1.000 \\
\hline \multicolumn{4}{|l|}{ Underlying diseases } \\
\hline Diabetes & $0(0.0 \%)$ & $2(1.8 \%)$ & 1.000 \\
\hline CAD & $0(0.0 \%)$ & $1(0.9 \%)$ & 1.000 \\
\hline Cardiac reoperation & $1(8.3 \%)$ & $2(1.8 \%)$ & 0.263 \\
\hline Renal dysfunction & $1(8.3 \%)$ & $3(2.7 \%)$ & 0.336 \\
\hline History of cerebral diseases & $2(16.7 \%)$ & $1(0.9 \%)$ & 0.024 \\
\hline History of anemia & $1(8.3 \%)$ & $7(6.2 \%)$ & 0.565 \\
\hline \multicolumn{4}{|l|}{ NYHA class } \\
\hline I & $0(0.0 \%)$ & $29(25.7 \%)$ & 0.078 \\
\hline$\|$ & 10(83.3\%) & $65(57.5 \%)$ & \\
\hline III & $1(8.3 \%)$ & 16(14.2\%) & \\
\hline IV & $1(8.3 \%)$ & $3(2.7 \%)$ & \\
\hline \multicolumn{4}{|l|}{ Etiologies } \\
\hline Hypertension & $7(58.3 \%)$ & $87(77.0 \%)$ & 0.291 \\
\hline Others & $5(41.7 \%)$ & $26(23.0 \%)$ & \\
\hline \multicolumn{4}{|l|}{ UCG } \\
\hline EF (\%) & $61.6 \pm 8.3$ & $60.8 \pm 7.9$ & 0.725 \\
\hline Pericardial effusion ${ }^{a}$ & $0(0.0 \%)$ & $5(4.4 \%)$ & 1.000 \\
\hline Aortic regurgitation ${ }^{b}$ & $1(8.3 \%)$ & $17(15.0 \%)$ & 1.000 \\
\hline \multicolumn{4}{|l|}{ Preoperative complications } \\
\hline $\mathrm{AMI}^{\mathrm{C}}$ & $1(8.3 \%)$ & $4(3.5 \%)$ & 0.402 \\
\hline Lower limb ischemia & $0(0.0 \%)$ & 16(14.2\%) & 0.361 \\
\hline Mesenteric artery infarction ${ }^{d}$ & $0(0.0 \%)$ & $7(6.2 \%)$ & 1.000 \\
\hline \multicolumn{4}{|l|}{ The scale of aortic dissection } \\
\hline Ascending aorta & $1(8.3 \%)$ & $4(3.5 \%)$ & 0.402 \\
\hline Aortic arch & $5(41.7 \%)$ & $48(42.5 \%)$ & 1.000 \\
\hline Innominate artery & $5(41.7 \%)$ & $23(20.4 \%)$ & 0.138 \\
\hline Right common carotid artery & $4(33.3 \%)$ & $14(12.4 \%)$ & 0.071 \\
\hline Left subclavian artery & $2(16.7 \%)$ & $10(8.8 \%)$ & 0.323 \\
\hline \multicolumn{4}{|l|}{ ASA status } \\
\hline I & $0(0.0 \%)$ & $0(0.0 \%)$ & 1.000 \\
\hline$\|$ & $0(0.0 \%)$ & $0(0.0 \%)$ & \\
\hline III & $0(0.0 \%)$ & $0(0.0 \%)$ & \\
\hline IV & $11(91.7 \%)$ & $10.5(92.9 \%)$ & \\
\hline
\end{tabular}

Table 1 Clinical data (Continued)

\begin{tabular}{llll}
\hline Category of clinical data & PCC (+) & PCC (-) & $P$ \\
$n=12$ & $n=113$ & \\
\hline V & $1(8.3 \%)$ & $8(7.1 \%)$ & \\
VI & $0(0.0 \%)$ & $0(0.0 \%)$ & \\
Euro SCORE II & $11.9 \pm 2.7$ & $9.0 \pm 3.4$ & 0.005 \\
\hline
\end{tabular}

The results demonstrated that the patients in the $\mathrm{PCC}(+)$ group were significantly older than the patients in the PCC(-) group, and the incidence of the preoperative cerebral disease history in the patients of the $\mathrm{PCC}(+)$ group was significantly higher than those of the PCC(-) group. The Euro SCORE II of patients in the $\mathrm{PCC}(+)$ group was dramatically higher than the patients of the $\mathrm{PCC}(-)$ group

$P C C$ Postoperative cerebral complications, $B M I$ Body mass index, CAD Coronary artery disease, NYHA New York Heart Association, UCG Ultracardiography, EF Ejection fraction, AMI Acute myocardial infarction, ASA American Society of Anesthesiologists

${ }^{a}$ serious pericardial effusion; ${ }^{b}$ serious aortic regurgitation; ${ }^{c}$ clinical manifestations, ECG, and contents of creatine kinase and troponin in the serum that were consistent with the diagnostic criteria for acute myocardial infarction; ${ }^{\mathrm{d}}$ confirmed by superior mesenteric artery angiography

postoperative intubation. Considering the impaired mental state and the poor spontaneous respiration of the patients, the physicians in the ICU prefer the prolonged assistance of mechanical ventilation in these patients after the surgeries for AAD. Therefore, it is almost inevitable that the incidences of postoperative ventilatorassociated pneumonia (VAP) and tracheotomy would increase.

A prolonged duration of mechanical ventilation assistance would certainly result in a prolonged ICU and hospital stays. A longer duration of ICU stay and ventilatory support would lead to a higher risk of multiple drugresistant bacterial infection and multiple organ dysfunction. In addition, it has been reported that the incidence of MODS in patients with severe stroke reached up to $34 \%$ [12]. Moreover, more elderly patients were observed in the PCC (+) group, which could be another risk factor for postoperative MODS. Therefore, it made sense that patients with PCC had a high rate of MODS.

A higher incidence of gastrointestinal complications was also observed in the patients in the PCC (+) group after surgery in this study. The probable reasons are: 1 . Neuromodulatory dysfunction as a result of cerebral ischemia, which could impair the hypothalamic-pituitaryadrenal axis and the sympathetic nervous system and finally destroy the gastrointestinal barrier function [13-15]; 2. Postoperative therapy of antiplatelet agents, anticoagulants and steroids, which are frequently applied to the patients after surgery for AAD; 3. Pulmonary infection, which was reported to be associated with development of gastrointestinal bleeding after acute stroke [16]; 4. Older age, which is another important risk factor for upper gastrointestinal bleeding according to one report [17]. Furthermore, because of the higher mortality due to pulmonary infection, MODS and GI complications which dramatically prolong the duration of ICU and hospital 
Table 2 Surgical and perioperative treatments

\begin{tabular}{|c|c|c|c|}
\hline Category of perioperative treatments & $\begin{array}{l}\text { PCC (+) } \\
n=12\end{array}$ & $\begin{array}{l}\text { PCC (-) } \\
n=113\end{array}$ & $P$ \\
\hline \multicolumn{4}{|l|}{ Types of surgical correction } \\
\hline Aortic sinus reconstruction & $3(25.0 \%)$ & $17(15.0 \%)$ & 0.406 \\
\hline Bentall & $1(8.3 \%)$ & $11(9.7 \%)$ & 1.000 \\
\hline Wheat & $0(0.0 \%)$ & $2(1.8 \%)$ & 1.000 \\
\hline Hemiarch replacement & $12(100 \%)$ & 106(93.8\%) & 1.000 \\
\hline Ascending aorta replacement & $12(100 \%)$ & 105(92.9\%) & 1.000 \\
\hline CABG & $0(0.0 \%)$ & $1(0.9 \%)$ & 1.000 \\
\hline \multicolumn{4}{|l|}{ Intraoperative conditions } \\
\hline Surgery (min) & $303.6 \pm 43.0$ & $282.4 \pm 55.9$ & 0.113 \\
\hline CPB (min) & $165.4 \pm 42.5$ & $134.8 \pm 21.5$ & 0.010 \\
\hline Aortic cross-clamping (min) & $50.8 \pm 7.6$ & $46.8 \pm 7.9$ & 0.064 \\
\hline $\mathrm{MHCA}+\mathrm{SCP}(\mathrm{min})$ & $20.3 \pm 2.1$ & $15.5 \pm 2.7$ & 0.000 \\
\hline Blood loss (ml) & $475.0 \pm 256.3$ & $374.8 \pm 166.5$ & 0.059 \\
\hline Avg $\mathrm{rCSO}_{2}$ baseline $(\%)^{a}$ & $48.2 \pm 3.3$ & $66.7 \pm 11.7$ & 0.000 \\
\hline Avg rcSO ${ }_{2}(\%)(L)$ & $56.5 \pm 8.2$ & $58.7 \pm 9.9$ & 0.505 \\
\hline Avg $\mathrm{rcSO}_{2}(\%)(\mathrm{R})$ & $57.3 \pm 7.1$ & $59.6 \pm 11.7$ & 0.560 \\
\hline $\mathrm{rcSO}_{2}$ minimum (\%) & $50.6 \pm 7.8$ & $54.7 \pm 7.3$ & 0.077 \\
\hline Total time of $\mathrm{rcSO}_{2}<70 \%$ baseline and $>15 \mathrm{~s}(\mathrm{n})$ & $4.6 \pm 1.8$ & $3.6 \pm 2.4$ & 0.174 \\
\hline Total time of $\mathrm{rCSO}_{2}<50 \%$ and $>15 \mathrm{~s}(\mathrm{n})$ & $1.7 \pm 1.0$ & $1.3 \pm 1.6$ & 0.099 \\
\hline AUC of $\mathrm{rCSO}_{2}<70 \%$ (\%min)(L) & $150.3 \pm 63.0$ & $121.2 \pm 75.5$ & 0.227 \\
\hline $\mathrm{AUC}$ of $\mathrm{rCSO}_{2}<70 \%(\% \mathrm{~min})(\mathrm{R})$ & $120.3 \pm 117.0$ & $98.5 \pm 63.5$ & 0.917 \\
\hline AUC of $\mathrm{rCSO}_{2}<50 \%$ (\%min)(L) & $86.6 \pm 62.7$ & $61.4 \pm 64.1$ & 0.145 \\
\hline $\mathrm{AUC}$ of $\mathrm{rCSO}_{2}<50 \%(\% \min )(\mathrm{R})$ & $52.7 \pm 32.3$ & $45.9 \pm 49.7$ & 0.303 \\
\hline Avg BIS index & $36.8 \pm 10.3$ & $39.8 \pm 9.3$ & 0.320 \\
\hline \multicolumn{4}{|l|}{ Perioperative allogeneic transfusion } \\
\hline $\mathrm{RBC}(\mathrm{u})$ & $2.7 \pm 1.8$ & $3.1 \pm 2.8$ & 0.727 \\
\hline $\mathrm{PLT}(\mathrm{u})$ & $0.8 \pm 1.2$ & $1.2 \pm 1.9$ & 0.201 \\
\hline FFP (ml) & $366.7 \pm 602.0$ & $313.7 \pm 345.8$ & 0.666 \\
\hline$C P(U)$ & $1.0 \pm 2.3$ & $1.5 \pm 2.8$ & 0.528 \\
\hline
\end{tabular}

The results demonstrated that there were significant differences between the two groups in terms of the duration of $\mathrm{CPB}$ and $\mathrm{MHCA}+\mathrm{SCP}$. The monitoring of $\mathrm{rcSO}_{2}$ indicated that there were no significant differences between the two groups in terms of intraoperative $\mathrm{rcSO}_{2}$ except for the average value of bilateral rcSO at baseline

$P C C$ Postoperative cerebral complications, $C A B G$ Coronary artery bypass grafting, $C P B$ Cardiopulmonary bypass, MHCA Moderate hypothermic circulatory arrest, $S C P$ Selective cerebral perfusion, $r C \mathrm{SO}_{2}$ regional cerebral oxygen saturation, AUC Area under the curve, RBC Red blood cell, PLT Platelet, FFP Fresh frozen plasma, $C P$ Cryoprecipitation

athe baseline value of $\mathrm{rCSO}_{2}$ from the bilateral brain before anesthesia induction

stay, the patients with PCC logically spent more money in hospital compared with the patients without PCC.

The survival rates of the patients after the surgeries between the two groups had no significant differences at the time of hospitalization and discharge. Nevertheless, we could find an increasing trend in mortality rates of the patients in the PCC (+) group. Therefore, we speculated that PCC plays an important role in the prognosis of patients after surgery for AAD, and this could be attributed to the high rates of postoperative pulmonary infection, gastrointestinal complications and MODS in the patients with PCC. Therefore, it is vital to evaluate the risk factors for PCC in these patients and to provide a scientific basis for an effective preventive strategy.

As we know, the main mechanism of postoperative cerebral dysfunction is an imbalance of oxygen metabolism in the brain which results from microemboli, hypothermia, hypoperfusion, hyperglycemia, reperfusion injury (RI), narcotics and internal environment disturbance. Moreover, a majority $(73 \%)$ of the patients in China were reported to be affected by a lack of an integral circle of Willis [18], and the intracranial artery 
Table 3 Short term outcomes and hospital costs

\begin{tabular}{|c|c|c|c|}
\hline Category & $\begin{array}{l}\text { PCC (+) } \\
n=12\end{array}$ & $\begin{array}{l}\text { PCC (-) } \\
n=113\end{array}$ & $P$ \\
\hline Anesthesia recovery period (h) ${ }^{a}$ & $19.5 \pm 33.0$ & $10.2 \pm 4.9$ & 0.072 \\
\hline New onset stroke & $2(16.7 \%)$ & $0(0.0 \%)$ & / \\
\hline Syncope & $1(8.3 \%)$ & $0(0.0 \%)$ & / \\
\hline POD & $2(16.7 \%)$ & $0(0.0 \%)$ & / \\
\hline POCD & $3(25.0 \%)$ & $0(0.0 \%)$ & / \\
\hline DEA & $2(16.7 \%)$ & $0(0.0 \%)$ & / \\
\hline Coma & $2(16.7 \%)$ & $0(0.0 \%)$ & / \\
\hline Total of cerebral complications & $12(100.0 \%)$ & $0(0.0 \%)$ & / \\
\hline Paraplegia & $1(8.3 \%)$ & $1(0.9 \%)$ & 0.183 \\
\hline Reoperation for bleeding & $0(0.0 \%)$ & $2(1.8 \%)$ & 1.000 \\
\hline Heart dysfunction ${ }^{b}$ & $0(0.0 \%)$ & $7(6.2 \%)$ & 1.000 \\
\hline Myocardial infarction & $0(0.0 \%)$ & $2(1.8 \%)$ & 1.000 \\
\hline Lethal arrhythmia & $0(0.0 \%)$ & $1(0.9 \%)$ & 1.000 \\
\hline Renal insufficiency ${ }^{c}$ & $1(8.3 \%)$ & $12(10.6 \%)$ & 1.000 \\
\hline Pulmonary infection & $6(50.0 \%)$ & $8(7.1 \%)$ & 0.000 \\
\hline Gastrointestinal complications $^{d}$ & $3(25.0 \%)$ & $6(5.3 \%)$ & 0.041 \\
\hline Wound infection & $0(0.0 \%)$ & $2(1.8 \%)$ & 1.000 \\
\hline Sepsis & $1(8.3 \%)$ & $5(4.4 \%)$ & 0.461 \\
\hline ARDS & $1(8.3 \%)$ & $3(2.7 \%)$ & 0.336 \\
\hline MODS & $3(25.0 \%)$ & $6(5.3 \%)$ & 0.041 \\
\hline ECMO assistance & $0(0.0 \%)$ & $2(1.8 \%)$ & 1.000 \\
\hline Thoracic drainage $\mathrm{e}^{\mathrm{e}}$ & $534.2 \pm 435.9$ & $471.9 \pm 504.3$ & 0.574 \\
\hline Intubation time(h) & $69.3 \pm 28.8$ & $33.3 \pm 24.2$ & 0.000 \\
\hline Tracheotomy & $4(33.3 \%)$ & $9(8.0 \%)$ & 0.022 \\
\hline Length of ICU stay(h) & $127.3 \pm 72.0$ & $63.5 \pm 51.3$ & 0.001 \\
\hline Length of hospital stay(d) & $32.0 \pm 16.7$ & $21.2 \pm 13.0$ & 0.009 \\
\hline Mortality in hospital & $1(8.3 \%)$ & $3(2.7 \%)$ & 0.336 \\
\hline Mortality after discharge & $1(8.3 \%)$ & $0(0.0 \%)$ & 0.096 \\
\hline Mortality after surgery ${ }^{f}$ & $2(16.7 \%)$ & $3(2.7 \%)$ & 0.072 \\
\hline Hospital costs (RMB) & $272,911.0 \pm 60,495.8$ & $224,651.5 \pm 61,219.9$ & 0.015 \\
\hline
\end{tabular}

Patients from the $\mathrm{PCC}(+)$ group were observed to have experienced significantly longer durations of intubation times, ICU stays, and postoperative hospital stays, and they also had dramatically higher rates of pulmonary infection, MODS and tracheotomy after surgery. The postoperative mortalities of the PCC(+) group had a trend of increasing, but there were no significant differences between the patients in these two groups. Patients from the $\mathrm{PCC}(+)$ group spent more money compared with the patients in the PCC(-) group

$P C C$ Postoperative cerebral complications, $P O D$ Postoperative delirium, $P O C D$ Postoperative cognitive dysfunction, DEA Delayed emergence from anesthesia, ARDS Acute respiratory distress syndrome, MODS Multiple organ dysfunction syndrome, ECMO Extracorporeal membrane oxygenation

${ }^{a}$ two patients with postoperative comas were not enrolled in the analysis of recovery times; ${ }^{b}$ severe heart failure reached NYHA grades III-IV; ${ }^{c}$ required renal replacement therapy; ${ }^{\mathrm{d}}$ included meteorism, nausea, vomiting, abdominal pain, diarrhea, constipation, and gastrointestinal hemorrhage; ${ }^{\mathrm{e}}$ within $48 \mathrm{~h}$ after surgery; ${ }^{f}$ up to the end of the follow-up period

atherosclerosis caused by uncontrolled hypertension, hyperglycemia, hypercholesterolemia, and obesity, which frequently occur in elderly patients and patients with a history of cerebral disease, may further impair the insufficient cerebrovascular cross-circulation [19-21]. Therefore, SCP will not meet the oxygen demands of the different regions of the brain.
The analysis in this study confirmed that the age, history of the cerebral disease, duration of $\mathrm{CPB}$, duration of $\mathrm{HCA}+\mathrm{SCP}$ and $\mathrm{rCSO}_{2}$ baseline were the potential risk factors of $\mathrm{PCC}$ during the preliminary statistical analysis in this study. Moreover, the multivariate logistic regression analysis revealed that the duration of $\mathrm{MHCA}+\mathrm{SCP}$ and the average baseline value of $\mathrm{rCSO}_{2}$ from the 
Table 4 Multivariate logistic regression analysis

\begin{tabular}{lllllll}
\hline Risk factors & B & S.E. & Wald & df & Sig. & Exp(B) \\
\hline Age & 0.454 & 0.652 & 0.484 & 1 & 0.486 & 1.574 \\
History of cerebral diseases & -7.529 & 23.720 & 0.101 & 1 & 0.751 & 0.001 \\
Euro SCORE II & 1.376 & 0.704 & 3.822 & 1 & 0.051 & 3.958 \\
CPB (min) & 0.498 & 0.518 & 0.925 & 1 & 0.336 & 1.646 \\
MHCA + SCP (min) & 2.198 & 1.038 & 4.483 & 1 & 0.034 & 9.009 \\
Avg rCSO$_{2}$ at baseline & -2.527 & 0.963 & 6.889 & 1 & 0.009 & 0.080
\end{tabular}

The duration of $\mathrm{MHCA}+\mathrm{SCP}$ and the average value of $\mathrm{rCSO}_{2}$ at baseline were ultimately identified as significant risk factors (OR: 9.009, $P=0.034$ and OR: $0.080, P=0.009$ )

CPB Cardiopulmonary bypass, MHCA Moderate hypothermic circulatory arrest, $S C P$ Selective cerebral perfusion, $\mathrm{rCSO}_{2}$ regional cerebral oxygen saturation ${ }^{a}$ the average baseline value of $\mathrm{rCSO}_{2}$ from the bilateral brain before anesthesia induction

bilateral brain before anesthesia induction were the independent risk factors for PCC. This indicated that anoxia, hypothermia, hypoperfusion and RI could conceivably play significant roles in the occurrence of PCC. Since the branches of the aortic arch are frequently implicated, the low value of $\mathrm{rcO}_{2}$ at baseline was considered to be a part of the systematic malperfusion in the patients with $\mathrm{AAD}$. It was reported that a low value of $\mathrm{rcO}_{2}$ at baseline is an important predictive factor for the prognosis of patients who undergo cardiovascular surgeries. Although the $\mathrm{rcO}_{2}$ at baseline has a weak relationship $(\mathrm{OR}=0.080)$ with PCC in our study, surgeons and anesthesiologists should pay more attention to patients with a low value of $\mathrm{rcO}_{2}$ before induction. Currently, it is nearly impossible to doubt that cerebral malperfusion during the circulatory arrest seriously damages the function of the central nervous system (CNS) and the RI following the MHCA will make the damage worse because of the widely disseminated inflammation in the brain. To alleviate ischemic injury, the surgeons always try their best to shorten the duration of circulatory arrest by modifying the surgical procedures and reducing the patient's core body temperature to an appropriate range. Eight years ago, our department first reported a novel surgical procedure, the triple-branched stented graft implantation, which could be applied to cure AAD with a relatively short duration of systemic circulatory arrest and without a large amount of intraoperative blood loss [22].

However, there are some keypoints which should not be ignored by surgeons: first, the hypothermia itself and CPB methods may depress the regulatory functions of blood flow in the brain and may induce cerebral ischemia during the process of the SCP. A normal level of perfusion pressure or blood flow rate may mask the malperfusion of the CNS [23]; second, in addition to the side effects of the anesthetics, intraoperative stress, and internal environment imbalance, we should also consider the disadvantage of the monitoring of $\mathrm{rcSO}_{2}$ in that this monitoring only focuses on the imbalance of oxygen metabolism in the bilateral frontal lobe, and it is not sensitive to the abnormal statuses in the other regions of the brain outside of the frontal lobe. It would be much more appropriate to use a whole-brain oxygen saturation monitoring method or a real-time detection of the bilateral cerebrovascular blood flow by transcranial Doppler sonography (TCD) during the surgery [24]; and Third, cerebral hyperperfusion should be avoided.

Intraoperative monitoring of $\mathrm{rcSO}_{2}$ was traditionally considered to be a fairly reliable forecasting and preventive measure of $\mathrm{PCC}$, and in this study, the average value of $\mathrm{rCSO}_{2}$ baselines was found to be significantly lower in the patients with PCC compared with the patients in the PCC(-) group. However, the same tendency of $\mathrm{rcSO}_{2}$ did not occur during the surgeries in this study. Does that mean that the monitoring of $\mathrm{rCSO}_{2}$ during the aortic surgeries is unnecessary? Obviously, the answer is no. In the course of aortic surgeries, we have observed several dramatic drops of $\mathrm{rcSO}_{2}$, and an emergency plan was initiated immediately to deal with the anoxia in the brain. Afterwards, the cerebral oxygenation would greatly improve within 5 10 min for approximately $70 \%$ patients who underwent aortic surgeries. This revealed that the intraoperative monitoring of $\mathrm{rcSO}_{2}$ could provide a much earlier warning indication of cerebral hypoxia comparing with conventional monitoring methods. Therefore, $\mathrm{rcSO}_{2}$ is considered to be an essential monitoring means during surgeries for AAD.

This study has several limitations. First, this retrospective case-control and single-center study could not ensure that the patients from the two groups received uniform therapeutic strategies. The selection bias from the subjective judgment of the physicians should not be ignored. Second, due to the relatively small sample size, the absolute quantity of the patients with PCC was relatively small and might reduce the statistical efficiency. Third, we could not exclude the possibility of underestimated mortalities, which were attributed to the relatively short duration of the follow-up period. Therefore, larger sample sizes and more randomized, controlled tests are required for further validation of these procedures.

\section{Conclusions}

PCC has a serious influence on the prognoses of patients who undergo surgical treatment for AAD. The duration of MHCA+SCP and the average baseline value of $\mathrm{rcSO}_{2}$ from the bilateral brain before anesthesia induction were the risk factors for PCC. Surgeons and anesthesiologists should pay more attention to the patients with low values of $\mathrm{rCO}_{2}$ before induction, and shortening the length of $\mathrm{MHCA}+\mathrm{SCP}$ may be an effectively prophylactic measure to reduce the morbidity of $\mathrm{PCC}$ in the patients with AAD. Larger sample sizes and more randomized, controlled tests are required for further validation of these procedures. 


\section{Abbreviations}

AAD: Stanford type A aortic dissection; AMl: Acute myocardial infarction; ARDS: Acute respiratory distress syndrome; ASA: American Society of Anesthesiologists; AUC: Area under the curve; BIS: Bispectral index; BMI: Body mass index; CAD: Coronary artery disease; CAM-ICU: Confusion assessment method for the intensive care unit; CNS: Central nervous system; CP: Cryoprecipitation; CPB: Cardiopulmonary bypass; DEA: Delayed emergence from anesthesia; ECMO: Extracorporeal membrane oxygenation; EF: Ejection fraction; FFP: Fresh frozen plasma; GCS: Glasgow Coma Scale; LCOS: Low cardiac output syndrome; MAP: Mean arterial pressure; MHCA: Moderate hypothermic circulatory arrest; MODS: Multiple organ dysfunction syndrome; NIHSS: National Institutes of Health Stroke Scale; NYHA: New York Heart Association; PCC: Postoperative cerebral complications; PEEP: Positive end-expiratory pressure; $\mathrm{PetCO}_{2}$ : End tidal $\mathrm{CO}_{2}$ volumes; PLT: Platelet; POCD: Postoperative cognitive dysfunction; POD: Postoperative delirium; RASS: Richmond Agitation Sedation Scale; RBC: Red blood cell; $\mathrm{rCSO}_{2}$ : regional cerebral oxygen saturation; RI: Reperfusion injury; SCP: Selective cerebral perfusion; TCD: Transcranial Doppler sonography; TEE: Transesophageal echocardiography; UCG: Ultrasound cardiogram; VAP: Ventilator-associated pneumonia

\section{Acknowledgments}

The authors thank the patients who participated in the study and the research assistants and study coordinators who assisted with data collection and management of the study, including Qian-Zhen Li, Guan-Hua Fang, Liang-Liang Yan, Sheng Chen, Yun-Nan Hu, Ling-Fen Li, Jun-Jia He and Jia-Xing Zhang.

\section{Authors' contributions}

MF-C and YL performed the conception and design. LW-C supported the administration. $Y L$ and RM-L provided the study materials and patients' informations. MF-C and YL collected and assembled the data of patients. MF-C and YL analysed the data and performed the interpretation. $Y L$ wrote the manuscript. All authors read and approved the final manuscript.

\section{Funding}

Not applicable.

\section{Availability of data and materials}

The datasets generated and/or analysed during the current study are not publicly available due to the confidentiality agreement of our institution but are available from the corresponding author on reasonable request.

\section{Ethics approval and consent to participate}

The Ethics Committees of Fujian Medical University Union Hospital approved this retrospective study, and written informed consent was obtained from all patients.

\section{Consent for publication}

Written informed consent for publication was obtained from all participants.

\section{Competing interests}

The authors declare that they have no competing interests.

Received: 23 July 2019 Accepted: 30 September 2019

Published online: 22 October 2019

\section{References}

1. Di Bartolomeo R, Berretta P, Pantaleo A, Murana G, Cefarelli M, Alfonsi J et al. Long-term outcomes of open arch repair after a prior aortic operation: our experience in 154 patients. Ann Thorac Surg. 2017;103:1406-12. https://doi.org/10.1016/j.athoracsur.2016.08.090.

2. Cefarelli M, Murana G, Surace GG, Castrovinci S, Jafrancesco G, Kelder JC, et al. Elective aortic arch repair: factors influencing neurologic outcome in 791 patients. Ann Thorac Surg. 2017;104:2016-23. https://doi.org/10.1016/j. athoracsur.2017.05.009.

3. Czerny M, Krähenbühl E, Reineke D, Sodeck G, Englberger L, Weber A, et al. Mortality and neurologic injury after surgical repair with hypothermic circulatory arrest in acute and chronic proximal thoracic aortic pathology: effect of age on outcome. Circulation. 2011;124:1407-13. https://doi.org/10. 1161/CIRCULATIONAHA.110.010124.

4. Powers WJ, Rabinstein AA, Ackerson T, Adeoye OM, Bambakidis NC, Becker K, et al. 2018 guidelines for the early Management of Patients with Acute Ischemic Stroke: a guideline for healthcare professionals from the American Heart Association/ American Stroke Association. Stroke. 2018;49:e46-e110. https://doi.org/10.1161/STR.0000000000000158.

5. Brignole M, Moya A, de Lange FJ, Deharo JC, Elliott PM, et al. 2018 ESC guidelines for the diagnosis and management of syncope. Eur Heart J. 2018; 39:1883-948. https://doi.org/10.5603/KP.2018.0161.

6. Ely EW, Margolin R, Francis J, May L, Truman B, Speroff T, et al. Evaluation of delirium in critically ill patients: validation of the confusion assessment method for the intensive care unit (CAM-ICU). Crit Care Med. 2001;29:13709. https://doi.org/10.1097/00003246-200107000-00012.

7. Teasdale $G$, Jennett B. Assessment of coma and impaired consciousness. A practical scale. Lancet. 1974;2:81-4. https://doi.org/10.1016/S01406736(74)91639-0.

8. Tzabazis A, Miller C, Dobrow MF, Zheng K. Delayed emergence after anesthesia. J Clin Anesth. 2015;27:353-60. https://doi.org/10.1016/j.jclinane. 2015.03.023

9. Ely EW, Truman B, Shintani A, Thomason JW, Wheeler AP, Gordon S, et al. Monitoring sedation status over time in ICU patients: reliability and validity of the Richmond agitation-sedation scale (RASS). JAMA. 2003;289:2983-91. https://doi.org/10.1001/jama.289.22.2983.

10. Chen LW, Dai XF, Wu XJ, Liao DS, Hu YN, Zhang $H$, et al. Ascending aorta and Hemiarch replacement combined with modified triplebranched stent graft implantation for repair of acute DeBakey type I aortic dissection. Ann Thorac Surg. 2017;103:595-601. https://doi.org/10. 1016/j.athoracsur.2016.06.017.

11. Sun L, Qi R, Zhu J, Liu Y, Chang Q, Zheng J. Repair of acute type a dissection: our experiences and results. Ann Thorac Surg. 2011;91:1147-52. https://doi.org/10.1016/j.athoracsur.2010.12.005.

12. Qin W, Zhang $X$, Yang S, Li Y, Yuan J, Yang $L$, et al. Risk factors for multiple organ dysfunction syndrome in severe stroke patients. PLoS One. 2016;11: e0167189. https://doi.org/10.1371/journal.pone.0167189.

13. Liu YC, Qi ZW, Guo SG, Wang Z, Yu XZ, Ma S, et al. Role of corticotrophin releasing hormone in cerebral infarction-related gastrointestinal barrier dysfunction. World J Emerg Med. 2011;2:59-65.

14. Lin CJ, Hung JW, Cho CY, Tseng CY, Chen HY, Lin FC, et al. Poststroke constipation in the rehabilitation ward: incidence, clinical course and associated factors. Singapore Med J. 2013;54:624-9. https://doi.org/10. 11622/smedj.2013222.

15. Schaller BJ, Graf R, Jacobs AH. Pathophysiological changes of the gastrointestinal tract in ischemic stroke. Am J Gastroenterol. 2006;101: 1655-65.

16. Ji R, Wang D, Shen H, Pan Y, Liu G, et al. Interrelationship among common medical complications after acute stroke: pneumonia plays an important role. Stroke. 2013:44:3436-44. https://doi.org/10.1111/j.1572-0241.2006.00540.x.

17. Chen CM, Hsu HC, Chuang YW, Chang CH, Lin CH, Hong CZ. Study on factors affecting the occurrence of upper gastrointestinal bleeding in elderly acute stroke patients undergoing rehabilitation. J Nutr Health Aging. 2011 15:632-6. https://doi.org/10.1007/s12603-011-0052-2.

18. Li Q, Li J, LV F, Li K, Luo T, Xie P. A multidetector $C T$ angiography study of variations in the circle of Willis in a Chinese population. J Clin Neurosci. 2011;18:379-83. https://doi.org/10.1016/j.jocn.2010.07.137.

19. Bornfeldt KE, Tabas I. Insulin resistance, hyperglycemia, and atherosclerosis. Cell Metab. 2011;14:575-85. https://doi.org/10.1016/j. cmet.2011.07.015.

20. Bos D, van der Rijk MJ, Geeraedts TE, Hofman A, Krestin GP, Witteman JC, et al. Intracranial carotid artery atherosclerosis: prevalence and risk factors in the general population. Stroke. 2012;43:1878-84. https://doi.org/10.1161/ STROKEAHA.111.648667.

21. van Rooy MJ, Pretorius E. Obesity, hypertension and hypercholesterolemia as risk factors for atherosclerosis leading to ischemic events. Curr Med Chem. 2014;21:2121-9. https://doi.org/10.2174/ 0929867321666131227162950.

22. Chen LW, Dai XF, Lu L, Zhang GC, Cao H. Extensive primary repair of the thoracic aorta in acute type a aortic dissection by means of ascending aorta replacement combined with open placement of triple-branched stent graft: early results. Circulation. 2010;122:1373-8. https://doi.org/10.1161/ CIRCULATIONAHA.110.946012. 
23. Yu H, Wang L, Zhang H, Wei W, Chen Y, Tang W, et al. Effect of mild hypothermia on cerebral microcirculation in a murine cardiopulmonary resuscitation model. Microcirculation. 2019. https:/doi.org/10.1111/micc.12537.

24. Wang X, Ji B, Yang B, Liu G, Miao N, Yang J, et al. Real-time continuous neuromonitoring combines transcranial cerebral Doppler with near-infrared spectroscopy cerebral oxygen saturation during total aortic arch replacement procedure: a pilot study. ASAIO J. 2012;58:122-6. https://doi. org/10.1097/MAT.0b013e318241abd3.

\section{Publisher's Note}

Springer Nature remains neutral with regard to jurisdictional claims in published maps and institutional affiliations.

Ready to submit your research? Choose BMC and benefit from:

- fast, convenient online submission

- thorough peer review by experienced researchers in your field

- rapid publication on acceptance

- support for research data, including large and complex data types

- gold Open Access which fosters wider collaboration and increased citations

- maximum visibility for your research: over $100 \mathrm{M}$ website views per year

At $\mathrm{BMC}$, research is always in progress. 